\title{
SOME CRYSTAL GROWTH FEATURES OF SEA ICE*
}

\author{
By Kenneth O. Bennington \\ (Department of Atmospheric Sciences, University of Washington, Seattle, \\ Washington, U.S.A.)
}

\begin{abstract}
Laboratory studies of the supercooling and freezing of baths of sea-water are described and compared with features of natural sea ice. By using dyes the convection cells in the sea-water test baths could be studied, and the growth of crystals relative to this cell structure could be observed. Brine expelled by the separation of ice from the system commonly followed the pre-existing convection channels. Sections of sea ice are interpreted in the light of these observations, and sea ice is shown to inherit drainage channels and banding features from the characteristics of the parent liquid system.
\end{abstract}

RÉsumé. On décrit les études en laboratoire de la surfusion et du gel de bains d'eau de mer et on les compare avec les caractères de la glace de mer naturelle. On a pu étudier les cellules de convection dans les bains de mer testés, en utilisant des colorants, et la croissance des cristaux par rapport à la structure des cellules a pu ètre observée. L'expulsion de la saumure à la séparation de la glace du système, suit en général les canaux de convection pré-existants. Des sections de glace de mer sont interprétées à la lumière de ces observations et l'on montre que celle-ci hérite des voies d'écoulement et des genres de lien caractéristiques du système liquide originel.

Zusammenfassung. Laboratoriumsstudien über die Unterkühlung und das Gefrieren von Meerwasserbädern werden beschrieben und mit den Erscheinungen bei natürlichem Meereis verglichen. Durch Einfärben konnten die Konvektionszellen in den Versuchsbädern untersucht und das Wachstum der Kristalle in seiner Beziehung zu dieser Zellstruktur beobachtet werden. Salzsohle, die durch die Separation von Eis aus dem System abgeschieden wurde, folgte gewöhnlich den vorgegebenen Konvektionskanälen. Betrachtet man Schnitte von Meereis im Lichte dieser Beobachtungen, so lässt sich zeigen, dass Meereis die charakteristischen Drainagekanäle und Bänderungen der Stammflüssigkeit beibehält.

\section{INTRODUCTION}

A sea-ice sheet develops by a process that is quite different from that of fresh ice. Although the similarly oriented individual platelets composing sea-ice crystal are pure, other features of sea ice, principally the platelet arrangement with brine pockets between platelets (Dorsey, 1940, p. 234; Anderson and Weeks, 1958; Anderson, 1958, I 96o; Weeks and Anderson, I958; Assur, 1958), the crystal orientation and brine drainage channels, all indicate that the ice separated from a solution rather than from the pure liquid. Sea ice grows from water that is undergoing continuous convection whereas fresh ice grows after the water column has reached the temperature of maximum density and a reverse density gradient exists near the surface. For sea-water with a salinity greater than $24.7 \%$, the freezing point is above the temperature of maximum density (Thompson, 1932) and therefore surface sea-water normally will not freeze until the entire column undergoing convection has reached the freezing point for water of that salinity. The depth of this thermal convection column may be determined by a barrier such as a salinity-density gradient. A "halocline", a region where the salinity gradient is a maximum, has been described by Hela (1958, p. 33) for the Baltic Sea.

After ice crystals begin to form, the additional density currents imposed upon the continuous convection bring sea-water to the interface and control the temperature at the constant freezing point for water of that salinity and, in this respect, sea-water is again different from fresh water in that the temperature at the freezing interface is not held constant by the phase change; if sea-water did not undergo constant convection at its freezing point it would become stratified and act as a closed system, and each fraction of ice removed would leave a slightly more concentrated brine with a correspondingly reduced freezing point as demonstrated by Ringer (1906) and Nelson and Thompson (1954). Although this does take place it does so in a sporadic way under unstable conditions when there is no mixing disturbance from wind action.

* Contribution No. 77, Department of Atmospheric Sciences, University of Washington, Seattle. 
The "sea-water-sea ice" transition represents a density change from approximately $\mathrm{I} \cdot 025 \mathrm{~g} . / \mathrm{cm} .^{3}$ for the liquid to approximately $0.90 \mathrm{~g} . / \mathrm{cm} \cdot{ }^{3}$ for the solid and a salinity change from approximately $29 \%$ to $34 \%$ for the liquid to approximately $5 \%$ to $8 \%$ for the ice. The salinity of the original surface sea-water changes seasonally with freezing and thawing and with mixing from wind action. The amount of brine that is mechanically trapped by the ice (Sverdrup and others, I 942, p. 2 I 7) varies with agitation and the rate of growth; the brine is only temporarily retained. The much larger proportion of brine that is rejected after the separation of pure ice crystals starts is added to the already established convection currents and this exerts a major influence on the growth of sea ice. The interrelated effects of the mechanisms of the expulsion and the retention of salts on the development of the ice sheet are the main objectives of this study.

\section{Crystal Growth Features of Sea Ice}

Observations on natural sea ice indicate crystal orientations and intergrowths which are not readily attributable to the physical properties of the crystals. In order to sort out the relative significance of the crystal and system characteristics an examination of the work on crystallization in pure water provides some basic understandings.

The orientation of the crystals formed on the surface of fresh water has been reviewed in detail by Dorsey (1940, p. 409). He argues (p. 4I I ) that the optic axis probably initially forms parallel to the temperature gradient but may be disturbed by some mechanical effects such as a current forcing the axis out of alignment with the gradient. Shumskiy ( 1955) discusses the problem and considers that the degree of supercooling and the direction of heat emission for sublimation and congelation ice growing on a solid base (p. I $5^{8-165}$ ) have a profound effect on determining the orientation, particularly when the $c$-axis is oriented predominantly normal to the temperature gradient. Some very pertinent points on orientation are discussed by Lyons and Stoiber (1959) who also consider supercooling and temperature gradients significant and further discuss the fragmenting effect of wind action. They point out (p. I6) that the growth direction of ice dendrites, in systems where heat flow is into the liquid as in the case of supercooling (Chalmers, I958, p. 299), need not show any relation to the direction of thermal conductivity. They further argue (p. I 7) against thermal conductivity determining orientations, since Hillig ( 1958 ) showed that the growth rate in the basal plane is much greater than the growth rate in the $c$-axis direction even though the $c$-axis direction may have a higher thermal conductivity by perhaps 5 per cent as shown by Landauer and Plumb (1956).

Many of these factors which control the orientations of crystals grown from pure water are applicable where there is a supercooling influence from the container wall, consequently a description of the crystal growth process may not necessarily help explain features in natural ice. The study reported here, however, concerns the interpretation of features in natural sea ice from the characteristics of crystals grown from normal sea-water under as nearly natural conditions as possible.

Supercooling in sea-water may be expressed in a fashion quite different from that in fresh water. In pure water with surface heat emission "thermal" supercooling may take place by conduction which does not disturb the density stratification. The term thermal supercooling is used by metallurgists to indicate supercooling caused by heat extraction from the liquid at its surface (see Rutter, I958, p. 251). Sea-water, with surface heat emission, may supercool under continuous convection which terminates when the temperature of maximum density has been reached.

Experimental studies on sea-water may be arranged so that the crystal growth features are similar to those observed in metals. Laboratory apparatus requiring heat extraction from the bottom of a vessel permits stratified supercooling without the normal convection that 
takes place in sea-water (see Rutter, I958, p. 246). Depending on the initial supercooling, under conditions of heat extraction at the base of the water column, crystal growth may begin at, or even below, the temperature of maximum density and the crystals then extend into water of a lower degree of supercooling. The expelled impurities, that are unable to drain away by gravity, diffuse ahead of the advancing interface increasing the solute concentration which then requires a lower temperature for freezing to continue. If the temperature in the liquid adjacent to the interface is lower than the equilibrium liquidus temperature for that composition, then the liquid at that point is supercooled. This phenomenon is described and defined by Rutter and Chalmers (1953, p. 30) as "constitutional supercooling" (see Tiller and others, I953, p. I34). Its magnitude influences the form of the growing crystals (see Tiller and Rutter, I956; Bolling and others, 1956) but can exert only very minor control over any change in orientation.

Many of the features of sea ice, the network, of drainage channels and crystal orientation changes, are apparently not explained by observations on crystal growth in other systems, or with an experimental arrangement too unrelated to natural conditions. In order to gain some insight into the heat transfer, the mechanical influences of convection and the effects of supercooling on crystal growth in normal sea-water, some test baths were prepared. They were designed to duplicate natural conditions as closely as possible by providing for surface heat emission and reducing boundary effects with the use of material of low thermal conductivity to build a large-volume tank.

\section{Test Procedure}

The tanks were made of clear plastic (polymethyl methacrylate known under such trade names as "Lucite," "Perspex", and "Plexiglas") and were of 21 . capacity; $20 \mathrm{~cm}$. depth and Io $\mathrm{cm}$. sides. The sides and bottom of the tanks were insulated with clear plastic envelopes in which windows could be cut as desired and the bottom was further insulated with a thick mat. The temperatures were measured with a mercury thermometer reading to $0 \cdot \mathrm{OI}^{\circ} \mathrm{C}$. which was adjusted to approximately $-\mathrm{I} \cdot 3^{\circ} \mathrm{C}$. before immersion to avoid seeding the test bath. An indicator dye was used to trace the convection. Fluorescein proved most successful because it could be seen at extreme dilution. A very few milligrams were dissolved in $\sim 50 \mathrm{~cm} .{ }^{3}$ of normal sea-water and a drop of this solution was added to $\sim 200 \mathrm{~cm} .{ }^{3}$ of the normal sea water used in the test. No detectable density difference could be attributed to the dye.

A standard procedure was followed with all of the tests. The filtered sea-water at room temperature was carefully poured into the insulated container to avoid any splashing or wetting of the container wall above the water level. This prevented dendrites from developing on the container surface and then extending into and prematurely seeding the bath. A shield above the bath prevented fine ice crystals and dust particles from dropping onto the water surface. Occasionally the failure to supercool could be explained, but more commonly no reason could be identified. The experience with unpredictable crystallization in supercooled sea-water was similar to that described by Dorsey (1940, p. 416 and 638) for pure water.

Two series of tests were made. In one, normal sea-water was cooled with thorough mixing to $-1 \cdot 6^{\circ}$ to $-\mathrm{I} \cdot 7^{\circ} \mathrm{C}$. then a portion, about $200 \mathrm{~cm} . .^{3}$, was removed, a few drops of dilute dye solution were added, and the temperature of the fraction was raised to approximately $-\mathrm{I} \cdot 4^{\circ} \mathrm{C}$. to ensure a slightly lower density than the bath. The faintly dyed solution was then ladeled on top of the sea-water test bath. With ambient temperatures below the freezing point of normal sea-water, convection cells slowly developed and a very distinct mosaic pattern appeared at the surface. The boundaries between the clear and dyed solutions were sensibly vertical near the surface but tapered to cone shaped depressions which finally narrowed to tubular liquid drainage "channels". After crystallization began, the vertically extending dendrites advanced along, preserved and retained these structural features that developed 
in the liquid. Evidence of these cone-shaped drainage features is very common in natural sea ice as shown in Figure $\mathrm{I}$.

The second type of test was much less successful. In this series normal sea-water was supercooled to $-2^{\circ}$ to $-3^{\circ} \mathrm{C}$. before mixing and removal of a portion to which the dye was added. It was very difficult to avoid seeding a supercooled bath while stirring to obliterate any salinity or temperature gradient or trying to place the dyed solution on the surface. In the very few tests that could be completed, convection channels would develop as before, but if the lower zones were not supercooled to the temperature of maximum density or below, the convection cycles would quickly and completely mix the dye. If crystallization began at the surface the vertically advancing dendrites grew very rapidly and again grew around and preserved the convection channels that were established in the liquid.

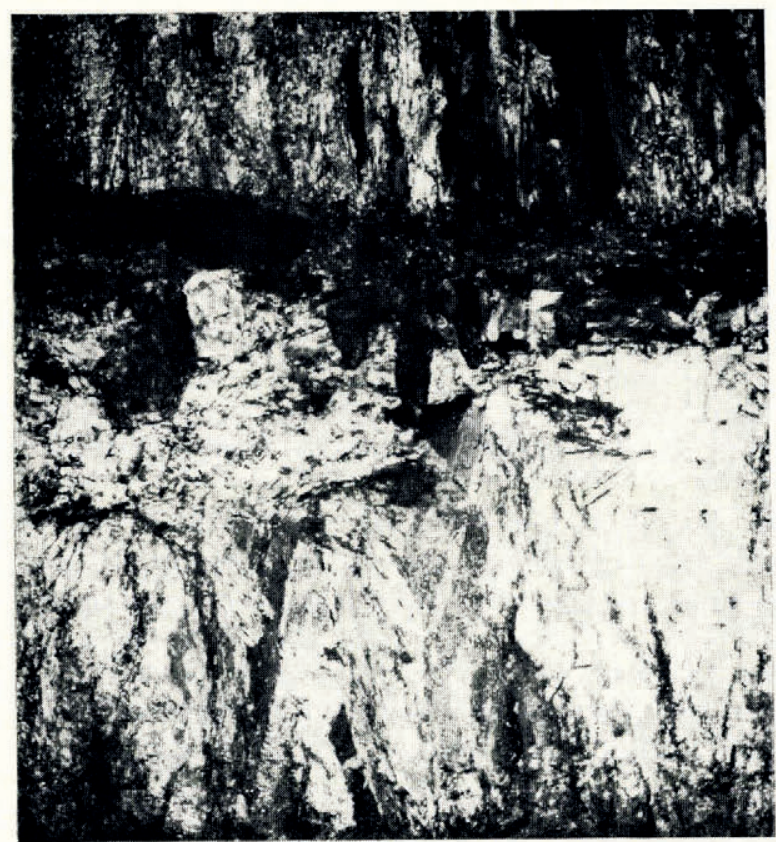

Fig. I. Brine drainage features in natural sea ice. Ice $8 \mathrm{~cm}$. thick from recently frozen lead. Top of specimen is sea-ice surface, bottom of specimen is sea-ice-water interface. Note "funnel" shaped platelet orientation feature from brine drainage. Brine corrosion pockets observable below thrust band. Vertical thin section is $4 \mathrm{~mm}$. thick. Between crossed polaroids

A bath was so easily seeded while attempting to use the dye solution that many tests were made with clear water. The normal liquid convection channels could very seldom be distinguished; however, after crystallization began, the streamers of expelled brine were very readily observed and could then be marked by a drop of dye solution.

Most of these tests were conducted at an ambient temperature that was between $-20^{\circ} \mathrm{C}$. and $-30^{\circ} \mathrm{C}$. The initial bath temperatures were $\sim 3{ }^{\circ} \mathrm{C}$. The bath would cool in a few minutes from this temperature to a temperature of $\sim_{\mathrm{I}} \cdot \mathrm{O}^{\circ} \mathrm{C}$. in the surface zone and $\sim-\mathrm{I} \cdot \mathrm{O}^{\circ} \mathrm{C}$. at the bottom. The surface zone was approximately $2.5 \mathrm{~cm}$. deep, the depth of convenient thermometer immersion. At these ambient temperatures the bath normally cooled so that the temperature difference between the surface and the bottom was $\sim_{2} \mathrm{C}$. ${ }^{\circ}$. The maximum temperature difference observed was $3 \mathrm{C}$. ${ }^{\circ}$ which was achieved as the lower zone approached the temperature of maximum density, $\sim-3 \cdot 6^{\circ} \mathrm{C}$. for water of this salinity, after which the gradient is quickly reduced to $\sim 0.2 \mathrm{C}$. ${ }^{\circ}$. The freezing point for sea-water of 
this salinity was $\sim-\mathrm{I} \cdot 8^{\circ} \mathrm{C}$. The lower zones in the test baths supercooled quite readily but crystallization normally prevented very pronounced supercooling at the surface. A few tests, however, did supercool to temperatures below the temperature of maximum density both at the surface, $\sim-4 \cdot 3^{\circ} \mathrm{C}$., and at the bottom, $\sim-4 \cdot 4^{\circ} \mathrm{C}$. The lowest temperature recorded was approximately $-7 \cdot \mathrm{I}^{\circ} \mathrm{C}$.

Crystal growth would very commonly take place when the surface was at a temperature of $\sim-1 \cdot 6^{\circ} \mathrm{C}$. and the bottom at $\sim-3 \cdot 5^{\circ} \mathrm{C}$. The initial dendritic crystals extended vertically downward from the surface at an increasing rate until the supercooling no longer existed. After crystal growth began the descending expelled brine streamers carried seed crystals to the lower regions. These minute seed crystals grew rapidly as they floated towards the advancing branched "interface". None of these dendrites were observed to extend into a convection "channel",

In a very few tests the ambient temperatures were near the freezing point for normal sea-water for prolonged periods, from $-\mathrm{I} \cdot 4^{\circ}$ to $-\mathrm{I} \cdot 8^{\circ} \mathrm{C}$. In these cases the initial crystal growth had the $c$-axis vertical and fine dendrites could be observed growing just beneath the meniscus.

A supercooled test was seeded before unaided crystallization began so that the process could be photographed (Fig. 2). A ring in the meniscus is apparent where the more concentrated and colder brine was deposited and below which the streamers of undyed brine may be observed. Single, planar, dendritic crystals commonly float initially with the $c$-axis horizontal, but rotate while ascending to a $c$-axis vertical orientation. Many free-floating dendritic growths assumed no apparent preferred orientation but upon contact with the advancing sea-ice "interface" provided a great variety of new growth directions. The very rapidly growing

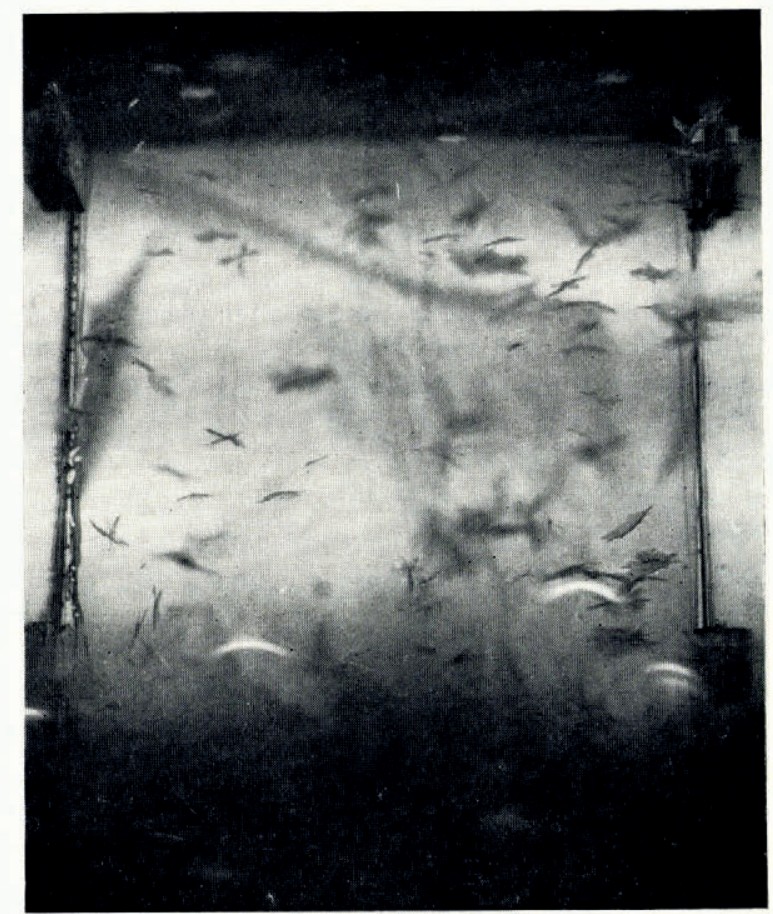

Fig. 2. Crystal development in supercooled normal sea-water. Greatest supercooling and fastest dendritic growth near bottom of tank, lower edge of photograph. c-axis vertical crystals are ascending; c-axis horizontal crystals have been swept down as fine needle crystals and are growing rapidly in supercooled zone. Vertical marginal lines are corners of tank $10 \mathrm{~cm}$. wide 
ascending dendritic crystals, interlocking upon contact, provided a temporary barrier to convection and were then capable of retaining a higher salinity than the ice mass composed of crystals with uniformly horizontal $c$-axes. Supercooling in these tests was very pronounced as compared with that under natural conditions, where dendritic growth was not observed.

Sea-water frozen in the transparent tanks did not solidify completely but always became an opaque mush. It was not possible to circulate normal sea-water at the proper temperature to duplicate open-system conditions without disturbing the dendritic crystals. In a closed system of this type with a progressively decreasing freezing point and increasing brine concentration, no attempt was made to obtain solid ice masses similar to natural sea ice. The test observations contributed to the understanding of some mechanisms involved in natural sea-ice growth.

One of the most significant factors derived from observations on the test baths was the occasional existence of a supercooled "zone". This supercooled zone is distinctly different from either thermal or constitutional supercooling as the zone develops from convection and may do so before crystallization begins. The formation of a supercooled zone or barrier qualitatively demonstrates a local heat-exchange process through convection at the interface rather than heat conduction through the liquid and solid respectively. Ultimately, of course, the heat loss must be through the surface. This part of the study is not complete and work is continuing with much better controlled laboratory apparatus. Special emphasis is being directed toward identifying the relative extent and influence of convection on constitutional supercooling.

Of the photographs presented in this paper, Figure 2 is the only one illustrating crystal growth conditions in the test baths. All other photographs are selected from those taken of block and core specimens that were collected from natural sea ice either off Point Barrow, Alaska or on Drifting Station ARLIS I during the winters of ig6o and I 96 I.

\section{Results and Some Interpretations from the Tests}

In pure water and water with any composition less than $24.7 \%$ salinity (the salinity at which the temperature of maximum density and the freezing point coincide) convection is terminated before the temperature reaches the freezing point. After freezing begins in waters of low salinity, convection will be re-established by the more concentrated expelled brine. The fine streamers of descending brine may be observed under properly reflected light without the use of dyes. Their location could commonly first be detected by the presence of extremely fine needle crystals in the interface between the expelled brine streamer and normal sea-water. These fine needle crystals grow into planar dendrites as they descend to the more supercooled region but as the branching increases the dendrites rotate away from the "channel" and begin their ascent. Repeated efforts to determine whether these fine crystals were seed crystals carried along with the brine streamer or whether they were actually nucleated in the interface were not definitive. The transport of seed crystals may be easily demonstrated by dropping dyed brine on a bath surface that is covered with dendrites, but attempts to demonstrate nucleation in the interface, even in supercooled systems, were inconclusive.

Supercooling at a halocline or barrier must be accomplished by the vertical currents. Whether the descending streamers of denser expelled brine are actually supercooled could be determined only with the identification of their true salinity and freezing point, their actual temperature must, however, be below the freezing point for normal sea-water. Crystals failed to grow into the "channel" because the streamers are of higher salinity and the "channel" was therefore preserved as a feature "inherited" from the liquid. The "channels" were never observed to be preserved in the tests by growth and accumulation of fine needle crystals in the vertical interface of the streamer. In systems where there is very little supercooling and 
there is less vigorous convection, the platelets in natural sea ice appear to grow around the "channel" as shown in Figure I.

If a barrier layer supercools, an extension of vertical platelets may take place towards this zone, or platelets may develop at the interface between the barrier layer and normal sea-water with the same horizontal attitude, or both processes may occur. With continued concentration of brine, the barrier layer will eventually cascade to a new level. The late passage of brine expelled from a band with vertical $c$-axis may leave the drainage channel opaque as shown in the natural sea-ice specimen in Figure 3.

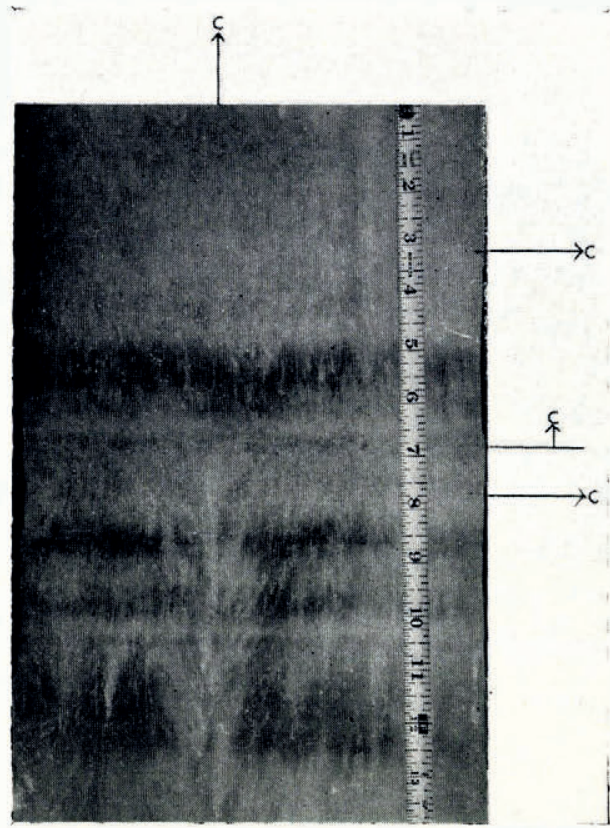

Fig. 3. Banded sea ice. Columnar crystal band with c-axes vertical from $I$ in. to $I \cdot 5$ in. and in 6.5 in. to 7 in. areas. c-axes horizontal in all other bands. Central drainage channel from the band of high brine content clearly developed. Vertical section ice plate $3 \mathrm{~cm}$. thick. Top of specimen is sea-ice surface. Photographed with incident light against black background. $I$ in. $=2.54 \mathrm{~cm}$.

Crystals in natural sea ice that grow with the $c$-axis vertical whether in the surface layer or a lower band, Figures 4, 5 and 6, very commonly show evidence of a former accumulation of brine at the base of the crystal. This temporarily trapped brine may be expelled or the buoyed up ice may permit it to drain away leaving a thermally insulating vug as shown in Figure 5, the brine having escaped through the lower crystal. The horizontal platelets and $c$-axis direction may be identified above the vug by the row of smaller brine pockets. The upward displacement of the ice has prevented re-entry of sea-water, consequently any healing has been minimized and the ice remains very porous.

A special procedure was developed to bring out the grain boundaries and structural features in such natural sea-ice specimens as that shown in Figure 4. The thin section was dressed to nearly the desired thickness, then quickly covered with a thin film of fluoresceindyed brine solution that was concentrated by freezing sea-water and then storing it at $-6^{\circ} \mathrm{C}$. The section was then turned upside down on a paper towel to drain, otherwise the brine would penetrate to the glass plate and cause the ice to slip free. After draining for several hours at $-25^{\circ} \mathrm{C}$., the ice thin section was again dressed to remove excess brine and dye leaving only 
the dye that filled vugs and penetrated along crystal boundaries. The photographic technique was to expose first between crossed polaroids with transmitted light, which identified individual crystals, then all lights were turned off, the upper polaroid was rotated out of the field, and the shutter was cocked for the second exposure; this was made with the surface of the specimen illuminated with ultraviolet light only, and the grain boundaries and structural features were thus emphasized by the fluorescence.

The thin white horizontal lines in Figure 7 represent the platelet edges of crystals oriented with their $c$-axes vertical and also appear to correspond to Tyndall figures seen from a direction normal to the $c$-axis (Nakaya, 1956, pl. 7, no. r8). Distinct hexagonal vapor figures (see Nakaya, I956) can be seen in the massive ice shown in Figures 3 and 7 , when the $c$-axis vertical

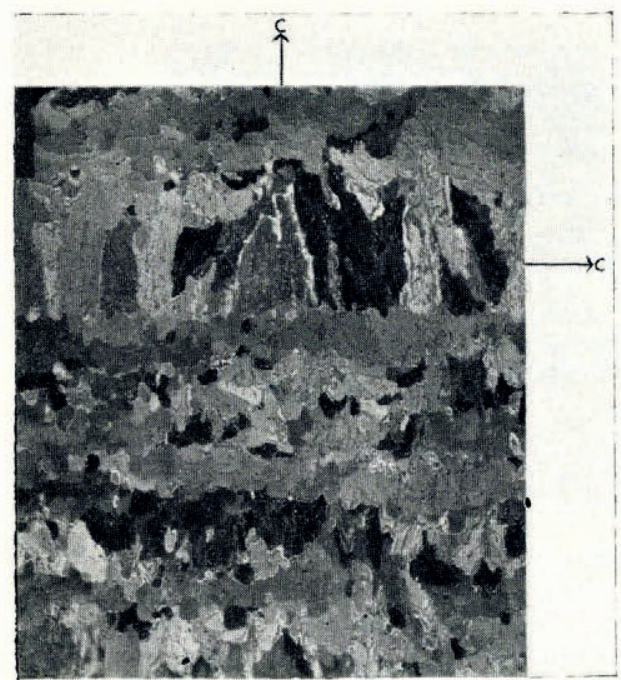

Fig. 4. Banded sea ice. Change in c-axis orientation from vertical in top band to horizontal in next band clearly visible. Top of specimen is sea-ice surface. Vertical section $7 \mathrm{~cm} . \times 10 \mathrm{~cm}$. and $1 \mathrm{~mm}$. thick. Double exposure of fluorescein dyed specimen. First exposure between crossed polaroids, second with incident ultraviolet light only to emphasize the structural features

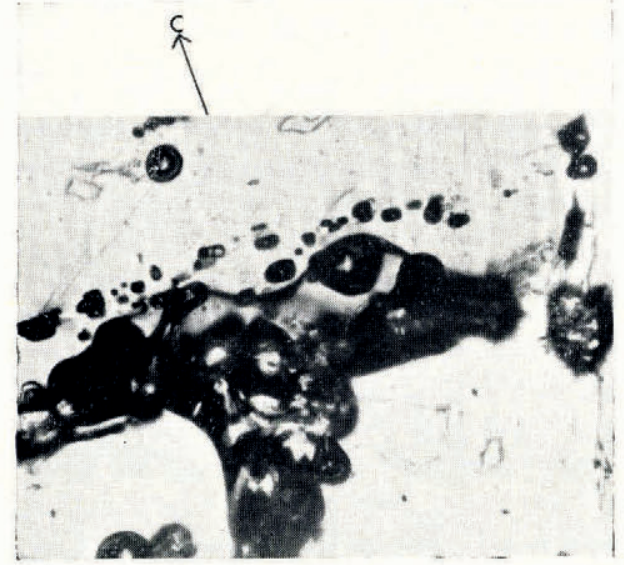

Fig. 5. Terminal brine pocket of columnar crystal. Horizontal platelets in upper crystal evident from row of small brine pockets. Drainage channel observable at crystal margin. Drained pocket (vug) provides thermal insulation. Vertical section $3 \mathrm{~mm} . \times$ $6 \mathrm{~mm}$. Top of specimen $6 \mathrm{~mm}$. below sea-ice surface. Between crossed Nicols 
crystals are viewed sub-parallel to the $c$-axis under reflected light. The circumstantial evidence is that these vapor figures originate from flat-lying platelets (dendrites) that develop as demonstrated in Figure 2. These vapor figures were never observed associated with $c$-axis horizontal crystals, indicating a possible relationship with slightly delayed brine drainage.

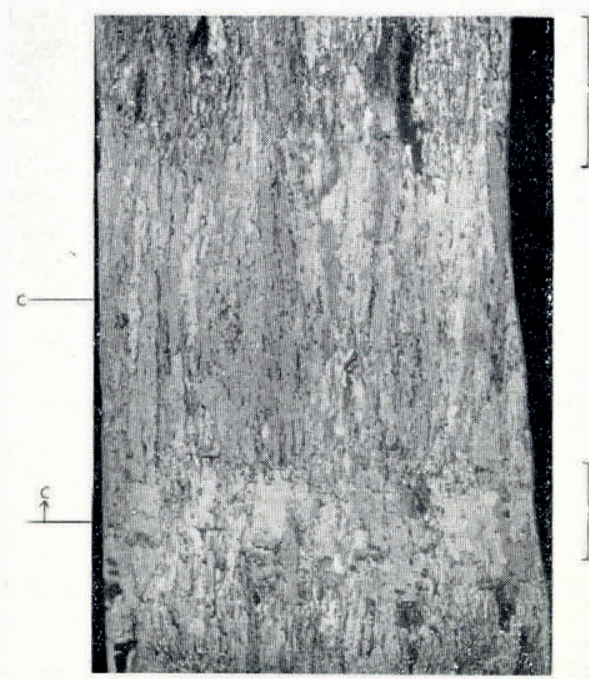

Fig. 6. Banded sea ice. Upper bracketed zone is the white band corresponding to the 4 in. to 5 in. zone in Figure 3 ; lower columnar crystal zone is the $6.5 \mathrm{in}$. to $7 \mathrm{in}$. vertical c-axis band. Note terminal brine pockets associated with the c-axis vertical crystals. Vertical section $6 \mathrm{~cm}$. X $10 \mathrm{~cm}$. Between crossed polaroids

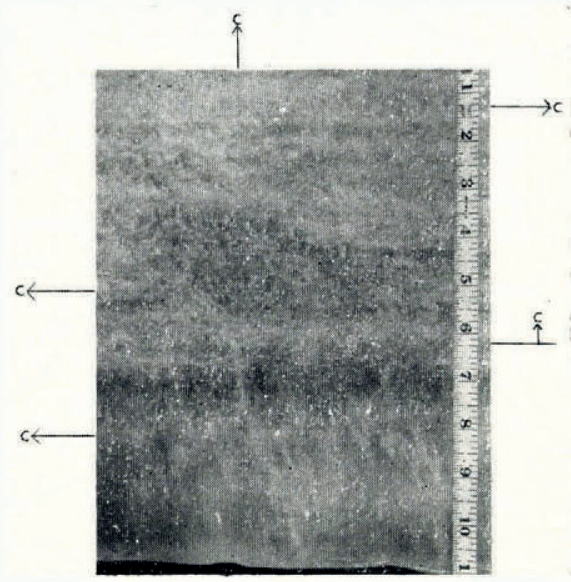

Fig. 7. Banded sea ice. c-axis vertial in top I in., horizontal from I in. to $1.5 \mathrm{in}$. and uniformly horizontal below 7 in. Fïne horizontal white lines appear as vapor figures when viewed vertically under reflected light. Top of specimen at sea-ice surface. Section $2 \mathrm{in} .(5 \mathrm{~cm}$.) thick and is photographed against black background under reflecled light. I in. $=2 \cdot 54 \mathrm{~cm}$.

\section{Crystal Orientation and Banding in Sea Ice}

The ice crystals that grow on the surface of sea-water, commonly with their $c$-axes vertical, have a greater tendency to trap brine than those that grow with their $c$-axes horizontal. The brine that is expelled during horizontal platelet growth cannot drain away as easily because of entrapment at the interstices formed at the junctions of the merging and inter- 
locking platelets from several columnar crystals. Before the concentrated brine escapes, its reduced freezing point retards continued growth either at the platelet edge or along the platelet face. After the concentrated brine escapes, re-entry of normal sea-water may be restricted and a vug may develop as the ice is buoyed up and the expelled brine continues to drain. These conditions, which are imposed by the system, favor the development of a crystal orientation that is not growth self-inhibiting. The platelets in a crystal with a horizontal $c$-axis are capable of extending continuously downward into the highest freezing point, and lowest salinity, sea-water.

Growth conditions near the surface may be capable of permitting either crystal orientation to grow at the expense of the other. A $c$-axis vertical crystal in Figure 8 has apparently forced a

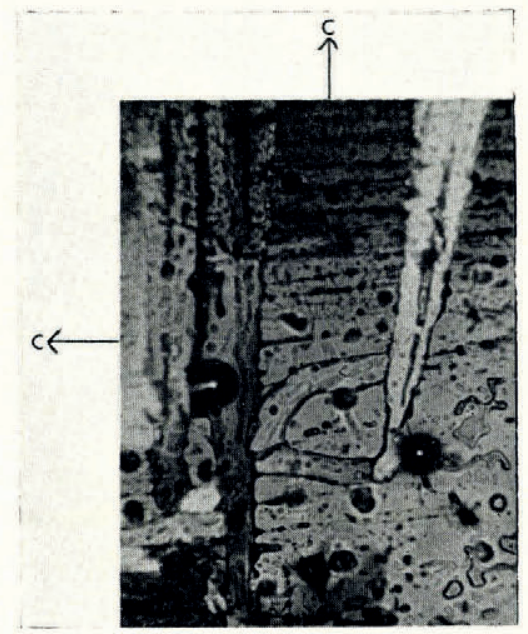

Fig. 8. c-axis vertical crystal crowding out c-axis horizontal crystals. Brine drainage channels evident. Top of specimen $2 \mathrm{~mm}$. below sea-ice surface. Vertical section $3 \mathrm{~mm} . \times 6 \mathrm{~mm}$. Between crossed Nicols

$c$-axis horizontal crystal to wedge out. Evidence of this nature was found only in the top I or $2 \mathrm{~cm}$. in sea ice and in this case successive sections could not be made to prove that it was not some peculiarity in platelet intergrowth. The channels near the tips of the vertically growing platelets indicate the possibility that these vertical platelets localized a convection cell and were unable to continue growth from the higher salinity expelled brine.

The surface crystals in Figure 9 are inclined but no evidence indicating a tendency for one to force another to wedge out was observed. Drainage channels were very clear in thin section and many appear near the arrow in the photograph. The explanation proposed here is that flat-lying or slightly inclined platelets in $c$-axis vertical crystals are unable to grow from the more concentrated brine trapped along or flowing across the platelet edges.

Sea-ice crystals at all levels in the ice sheet, are not consistently oriented with the $c$-axis horizontal as they are in the lower zones in very thick ice. The platelets may have a $c$-axis horizontal orientation at the upper surface and continue to greater depth but more commonly the surface crystals are not consistent, as shown in the vertical section in Figure 9, or contain distinct $c$-axis vertical banding as clearly shown in Figure 4, also a vertical section. The platelets in thick ice are commonly lenticular in cross-section, a feature that is more clearly expressed in the vertical section, Figure 10 , than in the horizontal section, Figure 11 . The section shown in Figure 10 is a vertical bottom section from a $160 \mathrm{~cm}$. core, and the section in Figure $\mathrm{I}$ is a horizontal core section taken from within $5 \mathrm{~cm}$. of the ice-water interface. 
The change in orientation of sea-ice crystals, from $c$-axis vertical to $c$-axis horizontal, as shown in Figures 3 and 4 , is a commonly repeated sequence. The zone of inclined crystals appearing at the surface in Figure 9 is less common and was not observed associated with the type of "banded" ice shown in Figure 3.

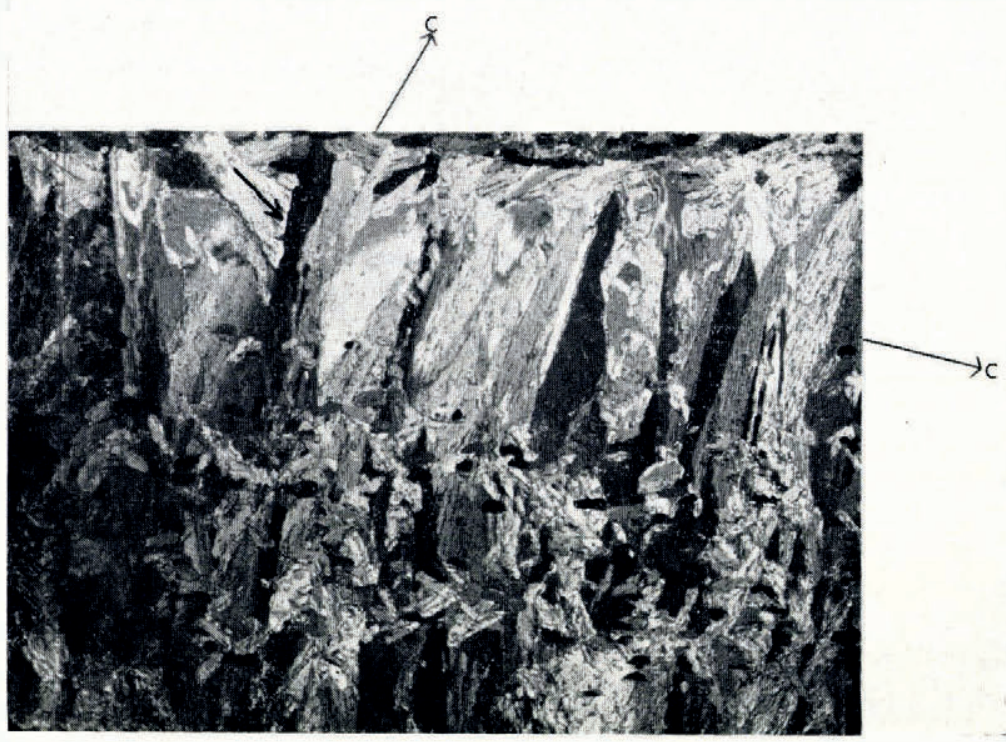

Fig. 9. Incipient banding. Vertically growing (c-axes horizontal) crystals advanced through incipient band of scattered c-axis sub-vertical platelets. Note fine drainage channel (arrow) across end of inclined crystal. Top of section at sea-ice surface. Vertical section $7 \mathrm{~cm} . \times 10 \mathrm{~cm}$. Between crossed polaroids

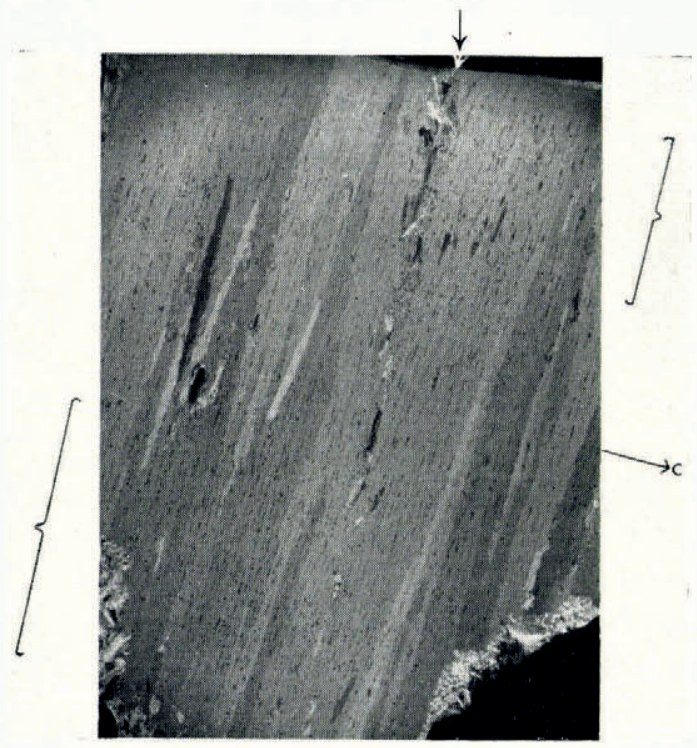

Fig. 10. Thin section of ice-water interface. Vertical section from bottom of $3 \mathrm{in} .(7.6 \mathrm{~cm}$.) core of $154 \mathrm{~cm}$. total depth. Drainage. channel, which is partially healed, (at arrow) transects vertical platelets and brine layers at small angle. Bracketed zones of greater porosity because of brine pockets along staggered intersections of smaller lenticular platelets. c-axes uniformly sub-horizontal. Section 3 in. $(7.6 \mathrm{~cm}$.) wide. Between crossed polaroids 
Zones of crystals of diverse orientation were occasionally observed in sea ice and it appeared possible for them to have originated from seed crystals that floated to the interface. The boundary between such a band and the next lower zone of $c$-axis horizontal crystals was of the type shown in Figures 3, 4 and 6. Evidence for a "wedging out" selection for the orientation in the next band, a mechanism described by Perey and Pounder (1958) was extremely rare. Observations on the test baths would indicate that some limbs of steeply dipping dendrites may "wedge out" limbs growing at a lower angle, but others may intergrow or cross in a dovetail manner without having been in contact and apparently without having disturbed the supercooling over the necessary distance to terminate the growth of the intersecting dendrite.

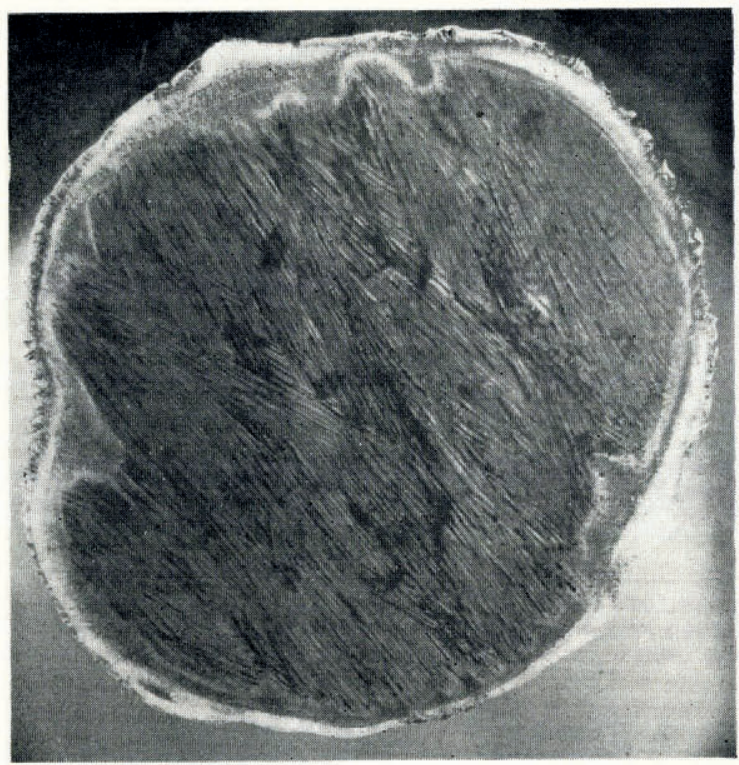

Fig. 11. Horizontal thin section from 3 in. $(7.6 \mathrm{~cm}$.) core cut $3 \mathrm{~cm}$. above ice-water interface. Black areas are drainage channels. Note intergrowths. Double exposure of fluorescein-dyed specimen. Thickness of specimen conceals effect of crossed polaroids. Maximum ice section diameler is $3 \mathrm{in.}(7 \cdot 6 \mathrm{~cm}$.). Fringe around platelet area is ice from pure water applied as "cement"

After growth direction has been established and any supercooling has been dissipated, growth continues by filling in of the dendrite and addition normal to the $c$-axis until the available space has been filled with no apparent tendency for other diverse orientations to develop. A cross-section of an ice specimen may show one set of platelets to terminate against another set when actually they have intergrown as shown in Figure 12, or were continuing growth in another direction.

The oriented intergrowths in natural sea ice (Fig. 12) appear to have formed from dendritic growth, which, however, was never observed in natural sea ice, not even leads frozen at temperatures below $-30^{\circ} \mathrm{C}$. Successive thin sections along the core continue to show the transecting inclusions with the same orientation as the major crystal. Harrison and Tiller (1963) have studied the interface morphologies during the solidification of sea-water. The intergrowths observed in natural sea ice appear to be capable of forming equally well from the cellular interface morphology described by them (p. 218). Their apparatus, however, required crystals to grow vertically upward expelling solute by diffusion. Under natural conditions expelled brine escaping by convection distinctly dominates over escape by diffusion. 
"Banding" in Arctic pack ice is very characteristic (Fig. 13) and may be observed at all levels in the ice. There are three distinct types of bands observable which may or may not all be found in any one section, but all of which are related to the characteristics of the sea-water system. One type, with crystals in a $c$-axis vertical orientation, is clearly shown in Figures 3,4 , 6 and 7 . Another type, consisting of high porosity zones from brine pockets along the staggered intersections of small lenticular platelets, is shown in the upper bracketed zone in Figure 6 and

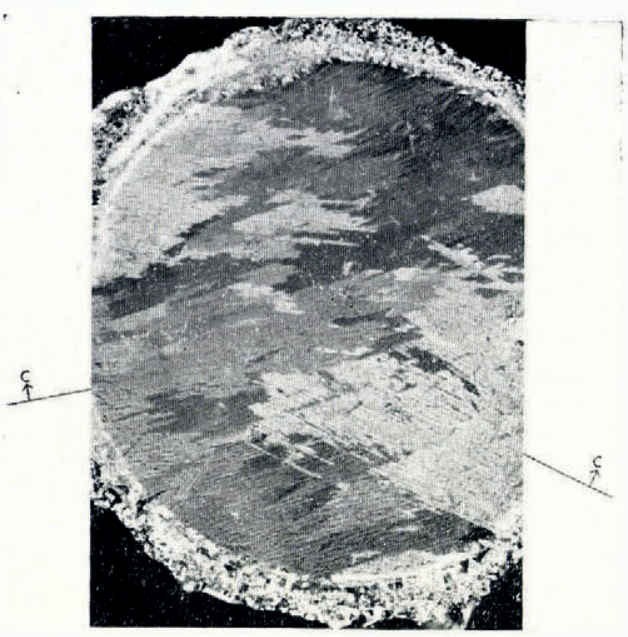

Fig. I2. Horizontal sea-ice thin section. From $150 \mathrm{~cm}$. zone in $3 \mathrm{in.}(7.6 \mathrm{~cm}$.) core of $160 \mathrm{~cm}$. total length. Note oriented intergrowths. Double exposure of dyed specimen. Maximum section diameter $3 \mathrm{in} .(7.6 \mathrm{~cm}$.) Outer fringe from pure water

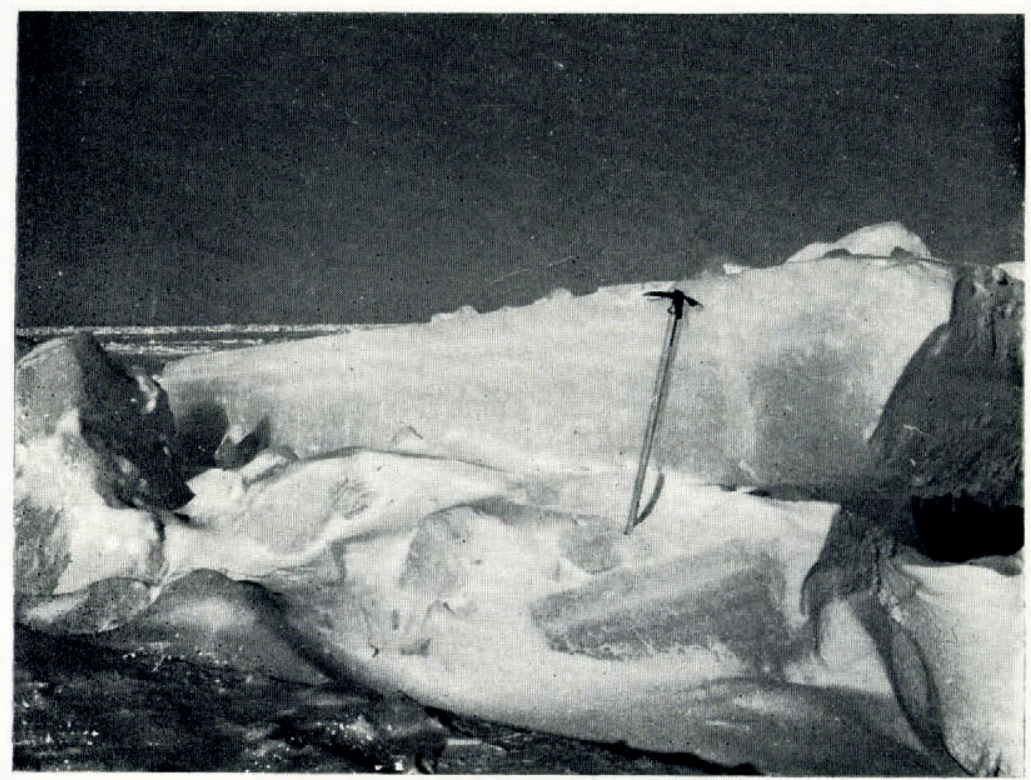

Fig. 13. Banded sea ice. Bands stand out clearly after sublimation 
the bracketed zones in Figure io. The other general type of band observed, shown in Figure I4, is formed by the expansion of trapped brine pockets. Another type of band, formed during deformation by thrusting on recently frozen leads (see Weeks and Anderson, 1958, p. 173) develops uniform, widespread and sometimes repeated banding, is easily identified and, since it is not directly related to crystal growth, will not be treated here.

The crystals in banded sea ice generally have their $c$-axes oriented distinctly either vertically or horizontally. The fairly uniform termination of platelets of $c$-axis horizontal crystals at an advancing front, as shown in Figures 3,4 and 6 , appears to be caused by a barrier at the interface, and the vertically advancing platelets are not able to grow through this zone until the freezing point of the more concentrated brine is reached. The boundaries of these bands are much more clearly expressed in vertical sections (Figs. 3, 4 and 6) than they are in horizontal sections for example Figure 15 which was cut through a vertical $c$-axis band; here the suboctahedral outlines of the individual $c$-axis vertical crystals is clearly shown, as are the occasional vertically extending platelets that have advanced into this band. These $c$-axis horizontal plates are capable of more rapid growth into a supercoooled layer between the advancing ice-water interface and the next barrier. For a barrier layer any supercooling would be nullified either by vertical $c$-axis growth or by occasional horizontal $c$-axis platelet advance through the zone before the horizontal platelets form an additional barrier. Such an "incipient" $c$-axis vertical band is shown in Figure 9, a vertical thin section cut from lead ice $10 \mathrm{~cm}$. thick that froze under quiet conditions at $-30^{\circ} \mathrm{C}$.

The interpretation here is that the origin of bands in natural sea ice, particularly those composed of alternating $c$-axis vertical and horizontal crystals, is restricted to conditions such that the supercooling of zones is possible. Occasional $c$-axis vertical crystals have been observed

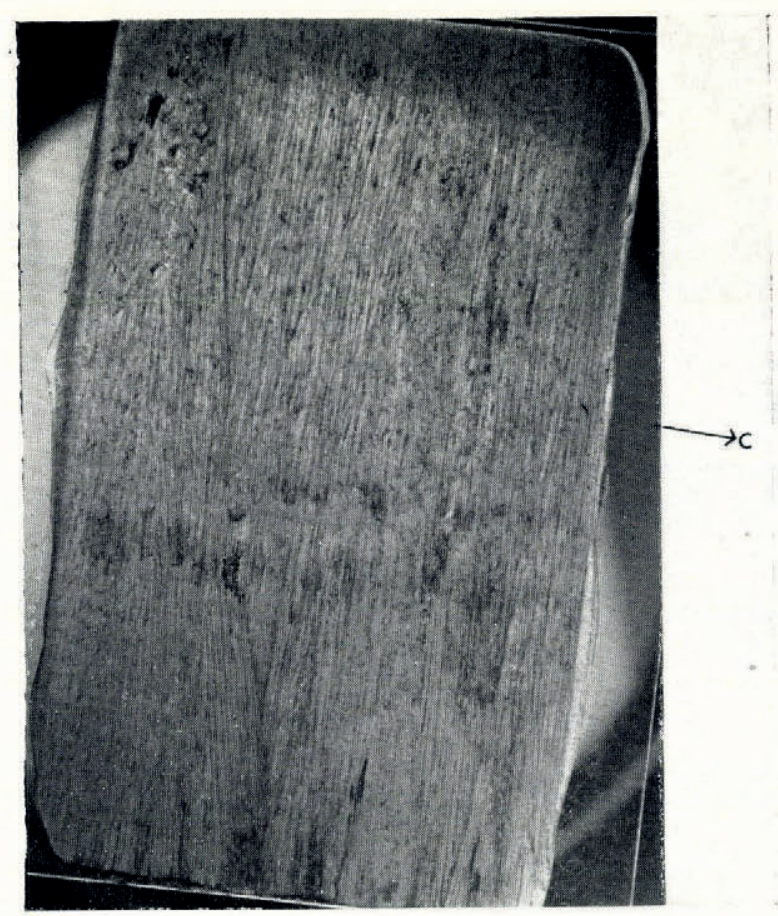

Fig. I4. Vertical thin section from bottom of $150 \mathrm{~cm}$. sea-ice core. Lower edge of specimen is ice-water interface. "Corrosion" band formed from brine-pocket expansion. Section $4 \mathrm{~mm}$. thick conceals effect of crossed polaroids. Double exposure of dyed specimen. Black spots and streaks are brine pockets, corrosion vugs and drainage channels. Core section $3 \mathrm{in} .(7 \cdot 6 \mathrm{~cm}$.) wide 
at all levels in sea ice that is $\sim_{\mathrm{I}} 60 \mathrm{~cm}$. thick, but bands have appeared only near the upper surface as shown in Figures 3 and 7 . Presumably sharp changes in the ambient temperature are so moderated at the growing interface in thick ice that mixing may take place in the liquid before a supercooled zone can form.

The observations on the test baths with dyes did not assist in determining the origin of the type bands in natural sea ice composed of lenticular platelets with a large number of brine pockets. These bands, the upper bracketed zone in Figure 6 and the bracketed zones in Figure Io, are scarcely visible in thin sections but are more apparent in larger blocks (Fig. I3) after sublimation has taken place and some of the brine pockets have drained. The mechanism proposed here for their origin is that a barrier layer forms but that supercooling is not sufficient

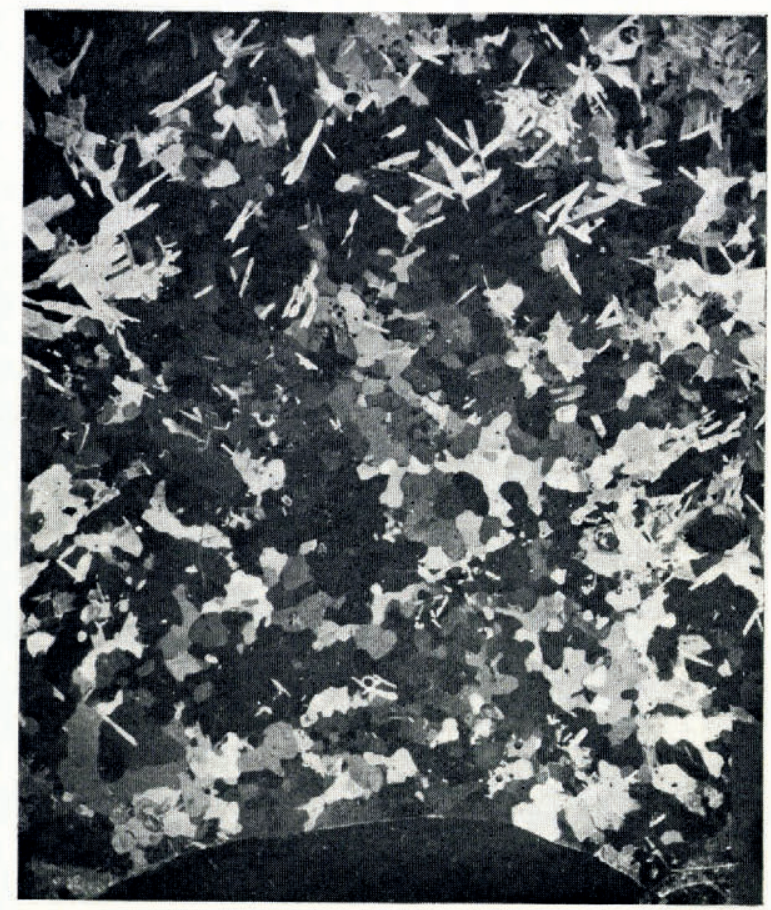

Fig. 15. Horizontal sea-ice thin section. Cut from vertical c-axis band, $6 \cdot 5^{-7}$ in. zone in Figures 3 and 6. Sub-octahedral crystal outlines visible, as are plates of c-axis horizontal crystals. Between crossed polaroids

to foster $c$-axis vertical crystal growth in the interface and a descending current does not seed the layer. The platelets advance into, and laterally within, the barrier layer, quickly dissipating any slight temperature advantage, and separate a large volume of brine with a progressively increasing concentration and density. The unstable layer cascades to a lower level leaving a greater proportion of brine pockets between the lenticular platelets and also leaving some platelets oriented along the drainage channel as shown in Figures $\mathrm{I}$ and 3 .

The third type of band observed, the "corrosion" type, formed by the expansion of trapped brine pockets, is shown in Figure I4. The photomicrograph (Fig. I6) of the band shown in Figure I4 was taken under crossed Nicols and presents the relationship between the brine pockets and platelets in greater detail. The light and shadowed areas in Figure 17 and in the platelets above the band and bordering the brine pocket zone in Figure 16 are pressure figures (also described by Knight, I962) and are clearly distinguishable between crossed Nicols. These pressure figures in sea ice indicate an internal stress concentration in the same sense 


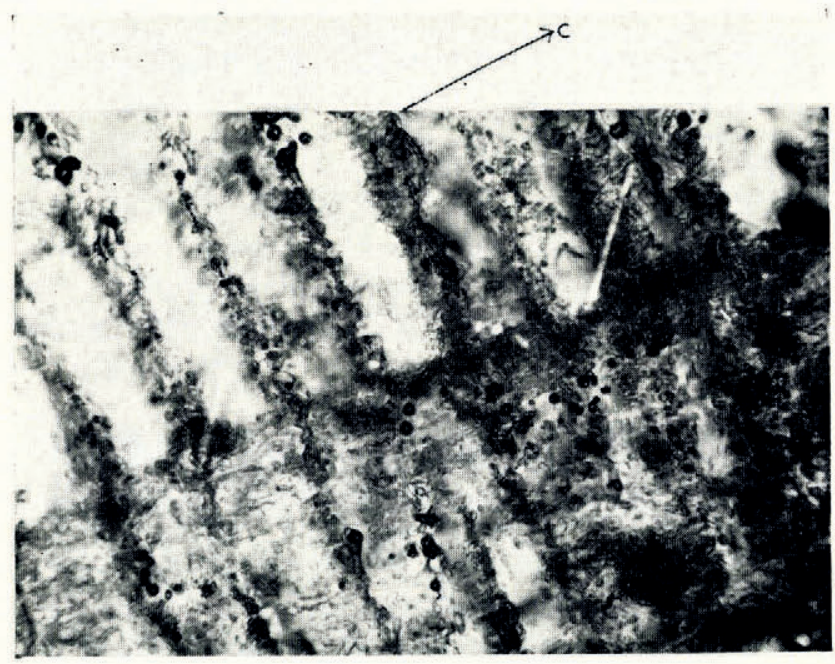

Fig. 16. Vertical thin section in sea ice. Corrosion band corresponds to that in Figure 14. Platelet thickness $0.5 \mathrm{~mm}$. Pressure shadows from expanding brine pockets. $\times 50$ between crossed Nicols

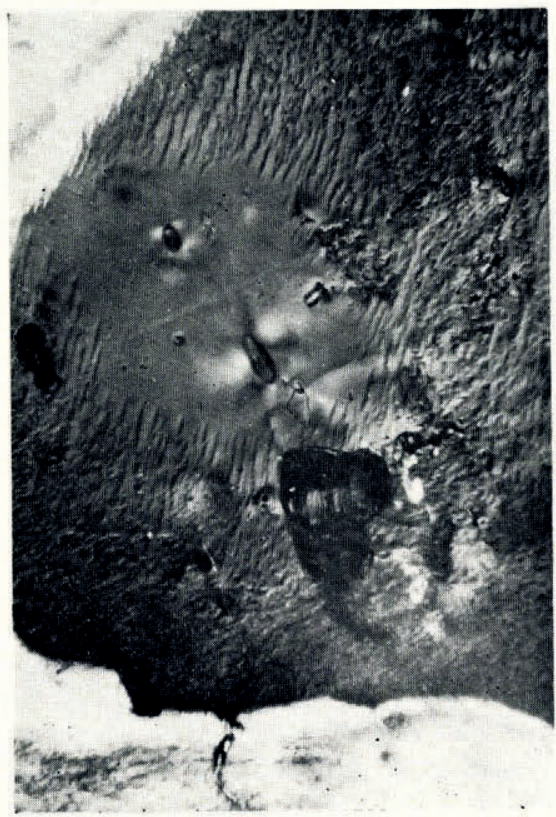

Fig. 17. Horizontal thin section of sea ice. Pressure shadows from internal stress developed by expanding brine pockets clearly expressed. $\times 50$ between crossed Nicols

that the dark cross indicates an internal stress produced by the freezing of liquid figures in single crystals of pure ice (Nakaya, I956, p. I5).

The "corrosion" bands are formed at a level in the ice where continuous circulation is restricted. The band shown in Figure 14 is approximately $4 \mathrm{~cm}$. above the ice-water interface. None of these bands was observed closer than approximately $3 \mathrm{~cm}$., or farther than $6 \mathrm{~cm}$., from the ice-water interface, and although successive bands were uncommon the few observed 
were approximately $3 \mathrm{~cm}$. apart. They appear to be formed because the volume increase from additional water frozen out of the concentrated brine in the brine pocket is great enough to create cracks and perforations that permit brine drainage. A similar type of liquid migration was demonstrated by Nakaya (1956, p. I5) on single crystals of pure ice. After an internal stress has developed from the partial freezing of a vapor figure a crack of nearly circular form is produced when the stress concentration exceeds the strength of the ice. He further observed that the remaining supercooled water in the liquid figure flows into the crack and freezes (p. 18) when the vapor figure is permitted to freeze completely. Nakaya also demonstrated the migration of vapor figures toward the high temperature side by a thermal gradient (p. $3 \mathrm{I}$ ), a problem which was earlier studied by Whitman ( 1926 ) on the brine migration in $\mathrm{NaCl}$ ice. The migration proceeds by evaporation from the warmer side of the figure or pocket and condensation on the colder side (Whitman, I926, p. I3 I; Nakaya, I956, p. 31). This work was recently re-examined by Kingery and Goodnow (ig63), who were unable to duplicate Whitman's migration counter to gravity. Although brine migration in sea ice may progress readily by the Whitman thermal gradient mechanism it is assumed here that the rate of brine migration may be greatly increased by repeated applications of the Nakaya internal stress mechanism, the changes in stress being caused by fluctuations in the ambient temperature.

The freezing of trapped brine pockets in sea ice takes place where the circulation of sea water is no longer continuous and the temperature is low enough to freeze additional ice and further concentrate the brine. The brine that is expelled through cracks or that "corrodes" its way to a drainage channel may then descend at a temperature that is below the freezing point for normal sea-water.

The greater thermal conductivity of the pure ice platelets permits a temperature change to be expressed more rapidly in the solid than in the brine pockets so that the brine dilution and migration takes place because of the non-equilibrium conditions that occur during slight temperature changes; a temperature decrease causing ice separation and an internal stress and a temperature increase causing the brine dilution "corrosion". This is the only band type identified that appears to require a fluctuating temperature for its formation.

There is no indication that the origin of the bands composed of crystals with vertical $c$-axis depends upon or requires a fluctuating temperature. The continuous convection in sea-water when subjected to freezing temperatures, the expulsion of brine after crystallization begins, the possible existence of a barrier, and the manner in which supercooling is expressed, all exist as characteristic attributes of the normal sea-water system under constant temperature. This does not exclude the possibility that the development of other types of banding may be enhanced by a fluctuating temperature.

None of the bands observed in sea ice appear to be comparable to the effect that has been called "banding" in metals. The banding in metallic crystals is formed from variations in concentration of solute that has segregated into alternate bands transverse to the direction of crystal growth. Their origin is explained as a result of fluctuations in the heat input to the liquid (Tiller and others, I953, p. 435; and see Rutter and Chalmers, 1953, p. 37)

\section{Discussion}

Under natural growth conditions the platelets of the skeleton layer (Weeks and Anderson, I958, p. 644) are in continuous communication with circulating sea-water or the more concentrated brine that is in the process of escaping. Slight compression of a "book" of platelets from a newly drawn core readily expells the brine retained between the platelets. The platelet edges terminate in a fairly uniform front which is referred to here as the ice-water interface even though, in some core and block specimens, occasional platelets extend perhaps $2 \mathrm{~cm}$. beyond the common front. In other specimens no variation of more than $\mathrm{I} \mathrm{mm}$, in platelet length was detected. Additional evidence from the corrosion bands indicates that the 
lower few centimeters are in at least sporadic hydraulic communication with sea-water. Some large drainage channels in the ice, of the type shown in Figure 5 , are $5 \mathrm{~mm}$. to $8 \mathrm{~mm}$. in diameter and permit sea-water to circulate distances from $20 \mathrm{~cm}$. to $45 \mathrm{~cm}$. from the interface during the freezing period in ice that is $160 \mathrm{~cm}$. thick.

In the test bath the most rapid advance of dendrites would generally border and roughly parallel an established descending convection current channel, consequently it is assumed that platelets that advance slightly beyond the uniform front in natural sea ice may have been influenced as much by the descending current as by either a stratified zone that may be supercooled, or represent the projections that may develop because of constitutional super-cooling (Rutter, 1958, p. 247). An influence of convection currents on crystallization velocity was reported by Tammann ( 1925 , p. 253). In these tests, after the initial temperature rise from dendritic growth and supercooling no longer existed, the temperature followed the progressively decreasing freezing point for water of increasing salinity.

The relative extent and expression of the three common types of supercooling is not always easily identified, a few points seem clear in reference to ice crystal growth however: (i) "Thermal" supercooling may take place in fresh water with a reverse density gradient and only in the complete absence of crystal growth. (ii) Constitutional supercooling may exist adjacent to an advancing crystal interface in sea-water because of the compositional changes taking place as a result of the crystallization. (iii) A supercooled zone may form in sea-water either from convection or from brine expulsion associated with crystallization in another part of the system or both. Nuclei and seed crystals swept into the zone of crystal growth in an interface will quickly dissipate the supercooling.

The extent of supercooling under natural conditions where compositions are not exactly known is difficult to determine, particularly for supercooling in excess of the minimum required for crystal growth to take place. The attempt here has been to correlate some of the features found in natural sea ice with the physical properties under the conditions imposed on the normal sea-water system. Sea ice is therefore interpreted as a "residual" which has inherited its major structural features (drainage channels, banding and other crystal orientation and growth features) from the characteristics of the parent phase.

Supercooling, regardless of its nature, was not observed to exert a direct control over the orientation of ice crystals grown from normal sea-water under natural conditions. It is of secondary significance in that its existence influences the density, and since the supercooled zone is a heat sink it affects the availability of the material for crystal growth. Dendritic crystals were observed to advance progressively more rapidly into a zone of increasing degree of supercooling but this represents a change in growth rate of a crystal with an already established orientation, which also holds true for crystals growing under conditions of constitutional supercooling. These observations are in apparent agreement with those of Weinberg and Chalmers (1951, p. 387 ), who point out that the direction of dendritic growth appears to depend only on the crystallographic orientation of the parent crystal and not on the direction of solidification. They further show (1952, p. 494) that the presence of supercooling is essential for dendritic freezing, the dendrites advancing only in characteristic crystallographic directions. In their experimental work for these studies on metals they used "boats" permitting the crystals to grow horizontally.

Independent crystals that grow at an interface of a supercooled zone and normal sea-water follow the orientation of the interface (see Shumskiy, r955, p. I62) regardless of its attitude; other free and unattached crystals growing in the body of a supercooled system acquire an orientation only from the mechanical effects of convection (Dorsey, I940, p. 4I I ; Lyons and Stoiber, 1959) and buoyancy effects of the crystal, or acquire an orientation upon striking some obstruction. In all cases the crystals have assumed their orientation from the mechanical properties of the system, or from the differences in density, structure and ease of availability of the growth material, all of which are functionally related to the temperature. 
The availability of material for crystal growth has been discussed by Chalmers (1954) with reference, in part, to the molecular orientation in the liquid at the interface which he has termed the "accommodation coefficient" (p. 520) coupled with compositional changes during crystal growth. From the many conditions considered, it appears that the generally observed consistent orientations of natural sea ice crystals are primarily related to two equally important factors when they are mutually supporting: fast crystal-growth direction (Hillig, I958) and the ease of availability of growth material.

\section{AcKnOWLedgements}

This work was sponsored by the Office of Naval Research through contract Nonr 477(24) to the University of Washington, Department of Atmospheric Sciences, administered by Dr. P. E. Church, Chairman of the Department. Grateful acknowledgement is tendered to P. E. Church, L. K. Coachman, J. D. Harrison and H. R. Peyton for suggestions in improving the manuscript. Observations for this study were made on Arctic drifting stations Charlie and ARLIS I, and at the Arctic Research Laboratory, Barrow, Alaska.

\section{MS. received 8 February 1963 and in revised form 17 May 1963}

\section{REFERENCES}

Anderson, D. L. 1958. A model for determining sea ice properties. (In Arctic sea ice. Washington, D.C., p. $148-52$. ([U.S.] National Academy of Sciences - National Research Council Publication 598.))

Anderson, D. L. I960. The physical constants of sea ice. Research, Vol. 13, No. 8, p. 310-18.

Anderson, D. L., and Weeks, W. F. 1958. A theoretical analysis of sea-ice strength. Transactions. American Geophysical Union, Vol. 39 , No. 4, p. $632-4$ o.

Assur, A. 1958. Composition of sea ice and its tensile strength. (In Arctic sea ice. Washington, D.C., p. $106-38$. ([U.S.] National Academy of Sciences - National Research Council Publication 598.)

Bolling, G. F., and others. 1956. Growth twins in germanium, by G. F. Bolling, W. A. Tiller and J. W. Rutter. Canadian Journal of Physics, Vol. 34, No. 3, p. 234-40.

Chalmers, B. 1954. Melting and freezing. Transactions of the American Institute of Mining and Metallurgical Engineers, Vol. 200. p. 519-32.

Chalmers, B. 1958. Growth of crystals of pure materials and of the solvents of solutions. (In Doremus, R. H., and others, ed. Growth and perfection of crystals: proceedings of an international conference on crystal growth held al Cooperstown, New York, 1958. Edited by R. H. Doremus, B. W. Roberts, D. Turnbull. New York, John Wiley and Sons, Inc., p. $292-309$.)

Dorsey, N. E. I940. Properties of ordinary water-substance in all its phases: water-vapor, water and all the ices. New York, Reinhold. (American Chemical Society. Monograph Series, No. 81.)

Harrison, J. D., and Tiller, W. A. 1963 . Controlled freezing of water. (In Kingery, W. D., ed. Ice and snow; properties, processes, and applications: proceedings of a conference held at the Massachusetts Institute of Technology, February I2-I6, 1962. Cambridge, Mass., The M.I.T. Press, p. 215-25.)

Hela, I. I 958. The Baltic as an object of ice studies. (In Arctic sea ice. Washington, D.C., p. 29-35. ([U.S.] National Academy of Sciences - National Research Council Publication 598.))

Hillig, W. B. 1958. The kinetics of freezing of ice in a direction perpendicular to the basal plane. (In Doremus, R. H., and others, ed. Growth and prefection of crystals: proceedings of an international conference on crystal growth held at Cooperstown, New York, 1958. Edited by R. H. Doremus, B. W. Roberts, D. Turnbull. New York, John Wiley and Sons, Inc., p. $350-60$.)

Kingery, W. D., and Goodnow, W. H. 1963. Brine migration in salt ice. (In Kingery, W. D., ed. Ice and snow; properties, processes, and applications: proceedings of a conference held at the Massachuselts Institute of Technology, February I2-16, 1962. Cambridge, Mass., The M.I.T. Press, p. 237-47.)

Knight, C. A. I962. Polygonization of aged sea ice. Journal of Geology, Vol. 7o, No. 2, p. 240-46.

Landauer, J. K., and Plumb, H. G. ${ }_{1} 956$. Measurements on anisotropy of thermal conductivity of ice. U.S. Snow, Ice and Permafrost Research Establishment. Research Paper 16.

Langway, C. C., jr. 1958. Ice fabrics and the universal stage. U.S. Snow, Ice and Permafrost Research Establishment. Technical Report 62.

Lyons, J. B., and Stoiber, R. E. 1959. Crystallographic orientation in lake and artificial ice. Bedford, Mass., Geophysics Research Directorate, U.S. Air Force Cambridge Research Center. (Scientific Report No. 2, Contract AF 19 (604)-2 I 59, AFCRL-TN-59-655.)

Nakaya, U. 1956. Properties of single crystals of ice revealed by internal melting. U.S. Snow, Ice and Permafrost Research Establishment. Research Paper 13. 
Nelson, K. H., and Thompson, T. G. 1954. Deposition of salts from sea water by frigid concentration. Fournal of Marine Research, Vol 13 , No. 2, p. 166-82.

Perey, F. G. J., and Pounder, E. R. 1958. Crystal orientation in ice sheets. Canadian Journal of Physics, Vol. 36 , No. 4, p. 494-502.

Ringer, W. E. 1906. De veranderingen in sammenstelling van zeewater bij het bevriezen. Chemisch Weekblad, Vol. 3, p. 223-49.

Rutter, J. W. I958. Imperfections resulting from solidification. (In Liquid metals and solidification: a seminar on liquid metals and solidification held during the 39 th national metal congress and exposition, Chicago, Nov. 2-8, 1957. Cleveland, Ohio, American Society for Metals, p. 243-45.)

Rutter, J. W., and Chalmers, B. 1953. A prismatic substructure found during solidification of metals. Canadian Journal of Physics, Vol. 31, No. 1, p. $15^{-39}$.

Shumskiy, P. A. I955. Osnovy strukturnogo ledovedeniya. Petrografiya presnogo l'da kak metod glyatsiologicheskogo issledovaniya. Moscow, Izdatel'stvo Akademii Nauk SSSR. [French translation: Principes de glaciologie structurale. La pétrographie de la glace comme méthode d'étude glaciologique. Annales du Centre d'Éludes et de Documentation Paléontologiques, No. 22, 1957.]

Sverdrup, H. U., and others. 1942 . The oceans: their physics, chemistry and general biology, by H. U. Sverdrup, M. W. Johnson and R. H. Fleming. Eaglewood Cliffs, N. J., Prentice-Hall, Inc.

Tammann, G. H. J. A. I925. The states of aggregation: the changes in the state of matter in their dependence upon pressure and temperature. Authorised translation from the second German edition by R. F. Mehl. New York, D. Van Nostrand Co.

Thompson, T. G. 1932. Physical properties of sea water. (In Oceanography. (Physics of the Earth, 5.) Bulletin of the [U.S.] National Research Council, No. 85, p. 63-94.)

Tiller, W. A., and others. 1953 . The redistribution of solute atoms during the solidification of metals, by W. A. Tiller, J. W. Rutter and B. Chalmers. Acta Metallurgica, Vol. I, No. 4, p. 428-37.

Tiller, W. A., and Rutter, J. W. 1956. The effect of growth conditions upon the solidification of binary alloy. Canadian fournal of Physics, Vol. 34 , No. 1, p. 96-121.

Weeks, W. F., and Anderson, D. L. 1958. An experimental study of strength of young sea ice. Transactions. American Geophysical Union, Vol. 39, No. 4, p. 641-47.

For details of Weinberg and Chalmers (1951), Weinberg and Chalmers (1952), Whitman (1926), see Journal of Glaciology, Vol. 5, No. 37, 1964, under "Errata". 